\title{
Integrating Agricultural Risks Management Strategies in Selected EU Partner Countries: Syria, Tunisia, Turkey
}

\author{
Fabio G. Santeramo, Fabian Capitanio, Felice Adinolfi*
}

\begin{abstract}
Dynamics and transitions in the agricultural sector of emerging countries are not yet well understood. A decade of major political and economic changes is challenging the Mediterranean Economies, affecting the primary sectors of transition economies which are largely influenced by recent trends. The resulting exposure of agriculture to risks has called great attention on risk management strategies and public intervention. We explore their role in three different economies with a view to a unified policy framework. The analysis is conducted through a field activity in Syria, Tunisia and Turkey that has allowed understanding the key issues. The experts' opinions draw a clear picture of retrospect and prospects and stimulate a comparative analysis that widens the current knowledge of risk management in the EU Partner Countries.
\end{abstract}

Keywords: EU Integration, Agricultural Policy, Partner Countries, Risk Management

JEL Codes: F15, N54, Q18

\footnotetext{
* Fabio G. Santeramo, Ph.D, is Assistant Professor at the University of Foggia, Italy. He has served as consultant in Economics for several International Organization (FAO, CIHEAM, IFPRI). He serves as co-editor for International Journal of Food and Agricultural Economics and as member of the Editorial Board for International Agricultural Policy . His area of research concerns agricultural economics, applied econometrics, and development economics. His articles have been published in Agricultural Economics, Journal of Policy Modeling, African Development Review, Tourism Economics, Food Reviews International. E-mail corresponding author: fabio.santeramo@unifg.it.

Fabian Capitanio, Ph.D, is Assistant Professor at the University of Naples "Federico II", Italy. He is currently serving as scientific expert assisting the European Parliament Committee on Agriculture and Rural Development. His area of research concerns agricultural economics, environmental economics, and development economics. His articles have been published in European Review of Agricultural Economics, Canadian Journal of Agricultural Economics, Applied Economics, British Food Journal. He has co-authored the book "The Politics of Land and Food Scarcity" (with P. De Castro, F. Adinolfi, S. Di Falco, A. Di Mambro). E-mail: capitani@unina.it.

Felice Adinolfi, Ph.D, is Professor in Agricultural Economics, University of Bologna, Italy. He is currently serving as external expert at the European Parliament, DG AGRI. He is co-editor of the review International Agricultural Policy. His articles have been published in European Review of Agricultural Economics, EuroChoices, British Food Journal. He has recently co-authored the book "The Politics of Land and Food Scarcity" (with P. De Castro, F. Capitanio, S. Di Falco, A. Di Mambro) E-mail: felice.adinolfi@unibo.it.

Acknowledgements: The authors wish to thank Selim Cagatay, Abderraouf Laajimi, and Firas Yassin for the fruitful discussions on the topic. A special thank to the referees and the editor for their helpful comments on the preliminary versions of the manuscript. We are solely responsible for the remaining errors. The authors gratefully acknowledge the funding support of the European Union 7FP project « Sustainable agri-food systems and rural development in the Mediterranean Partner Countries " (SUSTAINMED).
} 


\section{Introduction}

EU institutions are animatedly debating (e.g. the European Commission and Parliament, and the Member States' governments) on the opportunity for setting up a comprehensive EU-wide framework on risk and crises in agriculture. The proposed regulations on rural development for the period 2014 - 2020 confirm the previsions contained in Regulation $73 / 2009$ and introduce new interventions to help farmers cope with risks, and move toward a more integrated setting. Achieving a stronger degree of integration of agricultural systems is a main target to be pursued within and outside the European Union. The dialogues with Partner Countries have become more and more frequent and intense in order to facilitate their integration.

Over the last years the Mediterranean Countries have been interested in great political changes and wind of renovation that is certainly a break with the history: a great opportunity for the Mediterranean to move towards a more integrated system. The economy of Mediterranean countries, largely dependent on the primary sector, benefit from the numerous trade agreements linking the European Union and Partner Countries. The intensification of these agreements and the adoption of EU standards are major objectives of Mediterranean Countries ${ }^{1}$. The EU is not only alert on the dynamics of agricultural trade in Mediterranean Partner Countries (MPCs), but it is also interested in monitoring the status quo and the evolution of Partner Countries' agriculture (Nello, 2002; Spiridon, 2005).

Due to the increasing exposure of agricultural sectors to risks, the adoption of efficient strategies and policies to cope with risks has been largely indicated as a major priority on the EU agenda (Chatellier, 2011; Capitanio et al., 2013). The recent scientific debate has focused on the relevance and the synergies deriving from a correct implementation of risk management strategies at farm level and interventions supported at national or regional scale. In developing countries several factors need to be taken into considerations for a correct analysis of risk management strategies and policy intervention, such as farming systems, climate conditions, specific policies, institutional settings (Larson et al., 2006). Despite the fact that a vast literature is investigating the peculiarities of risk management strategies in developing countries and transition economies (e.g. Dercon, 2004; Mitu, 2007; Miranda and Gonzalez-Vega, 2011; Sambotin et al., 2013), the topic is still under-investigated in the Mediterranean Countries for which the lack of adequate risk management strategies and policy interventions call for ad hoc studies. Therefore, our analysis aims at exploring how Partner Countries compare with the European Union in terms of strategies and interventions to cope with risks in agriculture. In particular, we answer two specific questions: what is the status quo of risk management in Partner Countries; and which direction should Partner Countries follow to move toward a tighter integration with the EU agriculture.

In order to target these goals, we analyze and compare the status quo of risk management strategies and the policy interventions in three selected countries: Syria, Tunisia and Turkey. The set of countries is very heterogeneous and represents an ideal framework to analyze risk

\footnotetext{
${ }^{1}$ This phenomenon replicates the process that lead to EU enlargement. An important step of the EU enlargement to the Eastern Countries (Romania, Poland, Lithuania, etc.) has been the preparation of the candidate members' agriculture. The interested reader may refer to Nello (2002), Rollo (2004) and Giurca (2005) for excellent reviews of the issues related to EU enlargement and the agricultural sector.
} 
management strategies in countries with different degrees of integration with the European Union policies. In this perspective, the set of Countries represents an ideal framework to study how EU should guide Partner Countries to build efficient policies and strategies to cope with risks in agriculture.

By means of a field survey, several experts have been interviewed in order to provide valuable information to policymakers and to farmers. The paper provides policy implications for the design and administration of policies to cope with risks in the Mediterranean Countries. The structure of the article is as follows: next sections are aimed to describe the current situation and the challenges for risk management in developing and European Countries; the following section presents the results of our field survey; the last section provides final remarks for policy implications.

\section{Agriculture risks management in Developing Countries}

Developing Countries are exposed to a numerous set of risks; a simple classification might distinguish three categories: production risks, price and marketing risks, and financial risks (Table 1). The nature of agriculture, dependent on climate conditions, exposes the sector to production risks such as droughts, heavy rainfalls, frosts, storms, floods; pests infection and diseases which determine unexpected bad harvests are also relevant risks in developing agricultures and, in particular, affect field crops (e.g. wheat, barley, cotton, sugar beet, vegetables) and also trees and animal production. Price risks challenge the production side of free marketed crops; losses in products' quality and decreases in final price are the main risks faced by wholesalers and sellers. Finally, financial (e.g. the inability to access credit market) and institutional risks (e.g. risks of unexpected changes in the policy framework) are relevant to farmers' decisions (Santeramo et al., 2012).

Table 1 - Principal risks in Developing Countries primary sectors

\begin{tabular}{|c|c|c|c|c|}
\hline Type & Production risks & $\begin{array}{c}\text { Price-marketing } \\
\text { risks }\end{array}$ & $\begin{array}{l}\text { Financial } \\
\text { risks }\end{array}$ & Institutional risks \\
\hline Causes & $\begin{array}{c}\text { Adverse climate } \\
\text { conditions, pests } \\
\text { and diseases }\end{array}$ & $\begin{array}{l}\text { Inputs and output } \\
\text { price changes, bad } \\
\text { quality of harvested } \\
\text { produce }\end{array}$ & $\begin{array}{l}\text { Lack of } \\
\text { liquidity }\end{array}$ & $\begin{array}{c}\text { Sudden and } \\
\text { unexpected } \\
\text { policy changes }\end{array}$ \\
\hline $\begin{array}{l}\text { Crops } \\
\text { interested }\end{array}$ & Field crops & $\begin{array}{c}\text { Field crops; } \\
\text { Livestock }\end{array}$ & All crops & Subsidized crops \\
\hline
\end{tabular}

A different classification pertains to the nature of risks: systemic risks are collective risks, economy-wide, that is covariate risks that strike the majority of the community members or the entire homogenous region; idiosyncratic or individual risks in general, like illness or asset loss, affect only a particular individual. Previous studies in developing countries 
suggest that the idiosyncratic fraction of income risk is relatively high: for instance, Dercon (2002) found little correlation in incomes in different villages in India which indicates the prevalence of idiosyncratic risks rather than systemic risks; Morduch (2002), analyzing the same dataset, found that an idiosyncratic risk forms 75-96 percent of the total variance in income. The identification of the nature of risk is crucial in risk management; it is widely known that common risks are harder to be avoided as forms of risk-sharing fail. Collective risks cannot be shared, while idiosyncratic risks can be insured within the community more easily.

Formal and informal insurance transfers (credit or insurance) from outside the community or inter-temporal transfers such as depletion of individual or community level savings are very important to treat with common shocks and risks (Dercon 2004). Moreover, Alderman and Paxson (1994) demonstrate that common (covariate) shocks cannot be insured by risksharing as all members of the insurance pool would require payouts at the same time. As a result, the design of appropriate risk management policy interventions must take into account the relative magnitude of idiosyncratic and covariate shocks.

\section{Agricultural risks management in the European Union}

The topic of risk management in agriculture has always been at the margins of the European debate. The main reasons lie firstly in the structure of EU intervention, which, for nearly half a century, has effectively ensured the presence of mechanisms to stabilize the markets, while, secondly (in the subsequent development) of hedging instruments within individual Member States (MS). Those interventions are aimed at covering production risks, many of which have developed along very different trajectories, creating prospects for intervention that have not evolved according to common paths. This diversity of instruments available, the ongoing process of EU enlargement and the specific features of the various "agricultures", has led to a complex set of risk management systems in different Member States, which differ in the instrumentation available and the degree of coverage that the practices achieve ${ }^{2}$ (Capitanio et al., 2013).

With the phasing out of guarantees provided by the CAP to European farmers in terms of stabilizing the markets, the issue of risk management tools is gradually acquiring an ever more important role, this being reflected in a series of innovations that first appeared in the 2009 'Health Check' and then in the proposed Commission Regulation for rural development policy 2014-2020. With Article 68 of Regulation 73/2009, it is now possible to use part of the EU funds allocated for direct payments in order to promote farmers' access to risk management tools. An innovation that therefore concerns only the allocation of the resources and not the definition of the instruments themselves that remain a competence of the MS concerned. The forecast in question seeks to promote the management of production risks through incentives for insurance policies and the participation in mutual funds, to cover direct losses from specific events impacting negatively on the quantity and quality of farms such as poor weather, crop and animal diseases, environmental accidents and so forth ${ }^{3}$.

\footnotetext{
2 These innovations represent a novelty in the reform process of the Common Agricultural Policy which has been often characterized by minor changes, and therefore criticized by institutionalists (Lasan, 2012).

${ }^{3}$ The interested readers may refer to Capitanio et al. (2014) for further insights.
} 
With the changes introduced in the proposed regulations on rural development for the period 2014 - 2020, the Commission not only confirms the previsions contained in Regulation 73/2009 (placing them, however, in the multi-annual setting of the funding for actions to support rural development), but introduces a new measure, called IST (the Income Stabilization Tool), aimed at supporting risk management for the incomes of agricultural enterprises using mutual instruments.

The IST aims to create a safety net for farmers, protecting them from the negative consequences that may arise from adverse trends in income. A risk that encompasses not just production, but is all-encompassing, referring to the income of farmers, and therefore, all the adverse circumstances that might affect a farm's performance.

The IST therefore, while framed in the same logic of risk-management measures already available, is a much more ambitious tool, aiming to supplement and strengthen the safety net already provided by direct payments, but which discounts the absence of a connection with market trends.

\section{The field analysis}

The Delphi method consists of structural surveys and is based on a priori information of experts or agents involved at various stages in the primary sector. The methodology is designed as a group communication process aiming at achieving shared consensus on specific real-world issues through rounds of questionnaires delivered to a panel of experts (Hsu and Sandford, 2007).

We have coordinated three field surveys conducted in Syria, Tunisia and Turkey. The survey has been carried out by national experts through two-round questionnaires. The two rounds aimed at leading to successively more refined requests for expert opinion on risk management policies and strategies in Partner Countries' agriculture. The first round was intended to open up on the subject and discover as wide a range of perspectives as possible. In particular, it aimed to have a deeper insight into the following topics related to risk management: type of risks; spatial and temporal dimensions of risks; private strategies and policies to manage and cope with risks; and policy suggestions. The aim of the secondround was to consolidate experts' opinions trying to reach large consensus on key issues in risk management policies and strategies.

The first-round survey has been carried out in order to select experts and to ensure they were willing to participate in the Delphi survey. This stage also involved explaining the research topic, the objectives and the subsequent steps of the survey. The main sections of the first-round questionnaire have been set as to comprehensively cover the whole subject by asking mainly open-ended questions. The results of the first-round survey have been statistically analyzed for each study zone separately and used as input for the designing of the second-round questionnaires. The second-round questionnaires start with a brief description of the results of the first-round survey giving the experts a full picture about the collective experts' opinions reached in the first round. Therefore, the questionnaires maintain the same sequence of the main sections presented in the first-round while asking more specific questions. The questions, in general, ask the experts to agree or disagree with 
specific statements, to rank several options according to their importance or influence or to choose between different choices. The results are presented in the following sections.

Experts, policymakers at several Institutions, and farmers have been interviewed through the Delphi surveys conducted in Syria, Tunisia and Turkey during 2011 and 2012: explorative questionnaires provided insights on relevant issues such as types of risks, spatial and temporal dimensions of risks, private strategies and policies to manage and cope with risks, policy suggestions; successive rounds allowed to consolidate experts' opinions and reach consensuses.

In particular, the Delphi method in Syria has been conducted in three distinct agroclimatic zones, respectively located in the Latakia Governorate and the Aleppo Governorate, which are the main Farming Systems in Syria for their contribution to the national production of agricultural products. The selected Farming Systems are also representative for the main Syrian agricultural systems (NAPC, 2011).

As for Tunisia, the survey has been conducted interviewing experts involved at different stages of the supply chains, namely producers, input suppliers, wholesalers, credit providers, and insurers, and covered the two main areas in Tunisian agriculture: the Northwestern and the Central Western areas which produce the vast majority of cereals in the country. We investigated the main topics: the perception of risks, the risk-coping strategies and the policies implemented to reduce negative externalities.

Finally, the Delphi method in Turkey has been conducted by involving farmers and experts from main institutions (e.g. Ministry of Food Agriculture and Livestock, Agricultural Bank, Union of Agricultural Chambers, Agricultural Credit Cooperatives, Ege University). We have explored the main issues in risk management: types of risks, their perception, strategies to cope with them and the policy interventions. In particular, opinions of 30 experts were gathered mainly via face to face interviews. In addition, face to face interviews with about 50 farmers who are mostly engaged with fresh vegetable production in Antalya region were completed.

\section{Syria $^{4}$}

Wheat, cotton, vegetables, olives, and apples are the crops most exposed to price and market risks and experts argue that the lack of marketing culture and facilities are underlying problems. Production and yield risks - particularly frost, pest and diseases, and storm are secondary problems, while policy change risks and financial risks are perceived as negligible risks. The influence of international dynamics on income and expenditure are rather limited and local economies are currently barely affected by international dynamics. However the increasing liberalization is expected to expose farmers to a broader and more severe competition to the detriment of revenue stability.

The main strategies for risk-coping are the diversification of crops and income sources while more complex strategies (e.g. income skewing, specialization, precautionary savings

\footnotetext{
${ }^{4}$ It is important to point that the field survey has been completed in 2009 , before the starting of the civil war.
} 
and production/marketing contracts) have limited adoption. In particular, many experts argue that the diversification is attractive as it is perceived to be the most effective. Moreover, farmers tend to cultivate specialized crops - such as crops resistant to pest or drought - and to adopt specific agronomic techniques in order to cope ex-ante with risks. Nowadays it is also true that farmers have weak knowledge of alternative strategies, and mostly benefit from the government policies. As far as ex-post strategies are concerned, accessing informal and formal credit seem the most adopted, followed by consumption smoothing: the former is popular due to its simplicity and the absence of alternatives. Among the secondary strategies, recurring to formal credit and having members of the household employed in jobs outside agriculture are the most favored. Finally, strategies such as safety nets, support programs and welfare policies are rather negligible. According to the Delphi Method, farmers cope with price risks selling the products in distant markets, selling the products before harvesting or changing the containers with others of lower quality in order to reduce the marketing cost. Alternative strategies include changing crops or seeds and reducing the cultivated hectares. Moreover, farmers are skeptical to adopt advanced agronomical techniques to improve or stabilize yields.

As for the exposure to risks, a vast majority of experts argue that fruits are the most exposed specialty crops to price risks. In particular citrus, apricots, apples and peaches are largely exposed mainly due to their perishability and the lack of storage facilities. During the last decades, the introduction of new species and varieties helped to reduce price risks, showing a feasible and efficient way to cope with price risks (Wattenbach, 2006). Olive oil, an important cultivated crop in the Farming Systems under consideration, is the least exposed specialty crop to price risks: this is not surprising as olive oil can be easily stored for years. Farmers cope with price risks by selling their produce to distant markets, or by contracting the sale before harvesting. Moreover, as marketing costs account for a significant portion of realized price, marketers tend to reduce the quality of transportation facilities, such as the containers, to avoid losses due to unsold produce. Differently, farmers cope with olive oil production and yield risks by adopting agronomical techniques aimed to stabilize yields, thus reducing inter-seasonal fluctuations. Finally, farmers cope with policy changes risks by reducing inputs usage, in particular using reduced quantities of waters and fertilizers.

According to experts, farmers who do not have savings accounts usually save money in alternatives ways - e.g. buying houses, land, cars. Some experts argue that savings through bank account are limited by the necessity of (sufficient) liquidity to manage and improve farm infrastructures.

Agricultural cooperative banks are the main institution to access formal credit, while receiving personal loans from non-agricultural sectors is the most common way to access informal credit. As argued by a vast majority of experts, informal credit is likely to be costly, thus farmers are keener to access formal credit. However, there are several limitations in the formal market: firstly it is poorly managed; secondly, the lack of collaterals due to excessive land fragmentation limits the access to credit; thirdly, the complexity of procedures is a further friction in markets for formal credit. As for informal credit, experts argue its main limitation is due to excessively high interest. 


\section{Tunisia}

Experts argue that production and yield risks represent the main threats; market and financial risks are less important because the strong market intervention to ensure fixed prices limits market risks faced by farmers and consumers. A marginal role is played by policy changes and personal risks. Another significant source of risk is the increasingly limited availability of labor. Drought is the main climate risk affecting production, followed by rainfall, frost, storms which are closely related to the characteristics of the regions or the production systems. Finally, there is a vast consensus that the lack of inputs, particularly labor forces, farm organizations, and adequate facilities limit the potentiality of Tunisian agriculture.

The strategies adopted by farmers to cope with agricultural risk consist in ex-ante and ex-post strategies (Gurenko and Mahul, 2004). Among the set of ex-ante strategies, experts argue that diversification is the most adopted, followed by crops specialization and income diversification ${ }^{5}$. As for the latter, interviewees argue that the lack of funding limits investments in alternative businesses. Farmers tend to not prefer hedging while the adoption of insurance contracts is rather marginal. Consumption smoothing is the main ex-post instrument adopted by Tunisian farmers, followed by the access to informal and formal credit. Experts stress the importance of bank and financial networks, as well as of programs of public interventions. Finally, a marginal but significant role is played by mitigation instruments, such as diversification and acquisition of inter-temporal loans and rollover strategies.

According to experts, perishable products such as fruits and vegetables are the most exposed to price risks, while subsidized and storable crops (e.g. cereals) are the least exposed. International prices dynamics may affect farmers' income and food expenditures: volatility in international prices may have a negative impact on farmers' income, particularly on net sellers due to the high uncertainty they would face for input prices. In order to cope with price risks farmers tend to adopt several strategies: storage, diversification and production contracts are the most adopted. Production and yield risks are faced by adapting agronomic techniques as well as by selecting resistant and low-inputs crops. As for institutional and idiosyncratic risks, experts argue that a barely effective strategy is to constitute farmer unions; however those associations are not well developed yet and surely their contribution to risk management is limited.

Investments in livestock units, land or real estates are commonly adopted as forms of savings; financial savings through the formal banking system are rather limited. The main limits to savings are the low levels of farmers' income and its high variability.

Access to agricultural credit has particular salience in the context of Tunisian rural development (Foltz, 2004). The Tunisian government established a national agricultural bank (Banque Nationale Agricole) to provide credit to farmers, especially seasonal agricultural loans; farmers may get seasonal loans also from input suppliers or processing

\footnotetext{
${ }^{5}$ Diversification is a commonly adopted strategy in developing countries: small holders typically tend to diversify the gene pool of crops in order to cope with adverse shocks and to preserve the biodiversity (OECD, 2009).
} 
factories. They may access loans from other non-agricultural banks, particularly long-term loans for investments. Experts argue that access to the credit granting system is limited by the complicated procedures, such as the requirement of land guarantees, slow processes and long delays occurring between the credit request and the availability of funds; moreover the national cadastral recording covers only a small spectrum of the agricultural landscape. Finally, the high interest rates, accumulated indebtedness of farmers towards the bank and the subjective religious beliefs are the other typical problems faced by farmers in need for credit. As for the informal credit, widely adopted by farmers, the major problems are the high implicit interest rate and the long repayment period: this type of credit is therefore destined to cover some specific farm activities.

Experts conclude that Tunisian rural credit markets are not operating efficiently: most farmers are receiving credit from the informal sector, while only a small proportion is borrowing from banks. In fact, farmers with small land holdings do not hold land titles, and low household incomes are often excluded from the formal financial sector for agricultural credit (Foltz, 2003).

Insurance contracts are rarely adopted by farmers. Hail and fire are the main insurance damages covered by such contracts. However, the use of insurance contracts is still limited to a few cases, particularly when required by bank procedures. Interviewees consider that the high cost of the insurance contract and religious reasons are the main reasons explaining the low use of insurance programs. It is worth mentioning also that the insurance contracts available through insurance companies do not seem to adequately cover the wide range of risks and disasters perceived by farmers.

\section{Turkey}

Price and market risks are the main challenges for Turkish agriculture. In particular, the recent agricultural policy reforms towards decoupled payments and the alignment with international agreements, in addition to the lack of well-organized and well-operated agricultural markets have exposed the primary sector to main risks ${ }^{6}$. Price risks are sourced by fluctuations in input and output prices, although the former are less volatile. International dynamics affect domestic prices and export revenues; this results in a net decrease in farmers' incomes and purchasing power. Financial risks, the second category of importance, arise from the inability of farmers to access credits: the high and volatile interest rates and the liquidity constraints play a dominant role. Production risks are the third type of risks; the category includes natural disasters, pest and diseases, and quality of final products.

Income skewing (e.g. dilute harvest and marketing operations), specialization (e.g. the adoption of advanced agronomic techniques), and insurance contracts are the main ex ante strategies; asset liquidation is indeed the main ex post strategy. Farmers assert that making a prompt and right decision is the most efficient way to avoid risks; moreover they focus on plan farm operations rather than benefiting from technical assistance or farm recording systems. A vast majority of farmers are still interested in volumes of output disregarding the

\footnotetext{
${ }^{6}$ In particular strategic crops, namely wheat, cotton, barley, sugar and tobacco, that are regulated by the Government support policies, are exposed to excesses of supply, raising stocking costs, fall in output prices and yields.
} 
production processes and, in limited cases, are assisted by research institutions for technical assistance.

The irregularity of the production and the variability of the quality expose the industries of fruits and vegetables and of cotton to price risks: in order to avoid excessive losses farmers tend to destroy fresh products in case of overproduction. The use of insurance contracts and the diversification of crops to reduce yield risks are increasing. The formers cover fire, landslide, storm, whirlwind and, of course, damages due to hail. The latter is however limited by lacking extension services and adoption of traditional agronomical practices.

A vast majority of farmers do not save: the richest entrepreneurs in agriculture adopt investments in land and other industries as main forms of savings. Despite the credits provided by Agricultural Bank benefit of support policies, farmers show reluctance for insurance contracts due to several reasons: lack of confidence in insurer companies; complicated procedures required by credit companies; high premiums; solvency problems ${ }^{7}$. On the other hand, informal credits are limited by the high interest rates and the restricted periods for repayments.

\section{Discussion}

The results of our research are somewhat biased in the sense that they do not reflect the true and spontaneous reactions of stakeholders in the absence of policy intervention, particularly in the cereals subsector. For instance, cereals products and by-products being considered strategic in Tunisia, primarily for social stability, have been historically subject to price fixing at several levels by the public administration. Hence farmers and consumers are by-and-large protected against market price variability. Despite this situation, the cereals subsector is still exposed to many sources of risk which operators consider as real. The major device adopted by farmers to hedge against risks is the diversification of activities, either within the sector or outside. The result is not surprising. Indeed it confirms that crop diversification is a major risk-coping strategy in agriculture (Lin, 2011; Santeramo et al., 2013).

Moreover, our research conveys an important result. The use of instruments of protection against risks such as group work, production contracting or crop insurance is rather limited. The motivations of this contingent situation are both subjective and objective. On the one hand, public interventions on risk management in the selected Partner Countries do not have a long history and the insurance programs are rather inadequate; on the other hand farmers are reluctant to engage in risk-coping strategies, to sign insurance contracts, and have limited ability to provide guarantees and collaterals to acquire credit ${ }^{8}$.

While providing credit to farmers at preferential interest rates would make credit cheaper for them, past experiences (e.g. in Romania the subsidies were offered by the National

\footnotetext{
${ }^{7}$ Our results find support in previous studies that found that "the majority of small farmers prefer to borrow using a profit and loss sharing credit system rather than an interest based system, whereas larger farms and farmers with higher incomes prefer the interest based credit system" (Yazdani, 2006, p. 13).

${ }^{8}$ Such a difficulty is common in transition economies, and has been detected years ago in Central and Eastern European Countries by Swinnen and Gow (1999).
} 
Bank of Romania9) have shown that this solution is not the best. Instead, the creation of specialized agricultural credit institutions, widespread in Western European countries, has to be preferred.

\section{Conclusions}

The exposure of the agricultural sector to several sources of risks challenges developing countries and affects the primary sector of the European Partner Countries. The present paper analyzes the status quo in three selected Countries, namely Syria, Tunisia and Turkey and explores the role of risk management strategies and public interventions. We commented the results of extensive Delphi surveys conducted in the above mentioned countries.

We found that the primary sources of risks in the Mediterranean Countries are prices and markets dynamics due to the increasing volatility in input and output prices (Chatellier, 2011; Capitanio et al., 2013). In particular, experts argue that the process of trade liberalization and the bilateral agreements between Partner Countries and the European Union might tend to amplify the price volatility of domestic markets; rather than stabilizing prices (Cioffi et al., 2011). In agreement with previous studies (World Bank, 2005; Santeramo et al., 2012), we found that the lack of facilities, particularly storage and transportation facilities, is a major problem that leads to the insurgence and the intensification of market crises (Santeramo and Cioffi, 2012). A first and clear suggestion that emerges from our study is that Countries aiming at integrating more and more with the EU need to promote reforms that enhance the stability of the agricultural sector and the entire supply chain.

Furthermore, we found that diversification of crops and of income sources (e.g. smoothing consumption and self-insurance), are the most frequently adopted strategies to cope with risks. Farmers cultivate specialized crops (e.g. resistant to extreme weather conditions, pests or diseases) in order to stabilize yields and avoid low harvests, while suffering a structural lack of liquidity and difficulties in accessing formal and informal credit. Promoting the constitution of precautionary savings accounts to increase the ability of self insuring against frequent risks should be a priority on the policy interventions agenda. Furthermore, a solution for Mediterranean Countries would be to establish policies supporting weather index insurance in order to eliminate the moral hazard problem and reduce adverse selection (World Bank, 2005; Barnett and Mahul, 2007).

Lastly, in Mediterranean Countries the lack of experience in risk management strategies and the absence of effective public interventions expose the agricultural sector to severe risks: reduction in productive potential, vulnerability, and food insecurity (Pontrandolfi, 2013; Santeramo, forthcoming 2015). It is advisable to improve the current setting of agricultural policies through interventions directed towards the stabilization of incomes and in particular a special role needs to be played by the tools of risk management: the access to opportunities offered by devices for risk transfer, such as insurance contracts, should be improved.

\footnotetext{
${ }^{9}$ While agricultural producers received short-term credit at annual interest rate of $15 \%-60 \%$, the medium and longterm credit was available at annual interest rate of $70 \%-95 \%$ !
} 
Our study should not be exempt from criticisms. Firstly, our analysis relies on surveys. The lack of primary data may be a major limitation; however the characteristics of the countries analyzed, such as the lack of statistics, and a massive intervention of the government in agricultural activities through subsidies, make it unfeasible to study risk management by means of econometric or statistical techniques. Instead, our analysis is a promising starting point for policymakers interested in planning government interventions. Secondly, the analysis is limited to few countries and the results cannot be generalized to the entire Mediterranean area. However, the radical differences that characterize the selected countries render our set an ideal framework to understand how Partner Countries should reform their interventions to achieve a stronger integration with the European standards in the agricultural sector.

To sum up, our analysis shows that Partner Countries face similar challenges to those that the Eastern Countries have encountered (e.g. Romania, Bulgaria, etc.) before the EU enlargement. However, the current peculiarities of Mediterranean Countries have to be taken into account in order to promote economic integration. Emblematic cases are the civil war in Syria, and the marked religious differences among European Member States and Turkey. All in all, the current challenges call for further analyses of Partner Countries: the economic history of Eastern and transition economies would be an ideal framework of reference.

\section{References}

> Alderman, H., and C. Paxson (1994) "Do the Poor Insure? A Synthesis of the Literature on Risk and Consumption in Developing Countries". In D. Bacha, (ed.), Economics in a Changing World. Vol. 4: Development, Trade and the Environment. London: Macmillan.

$>$ Barnett, B., and O. Mahul (2007), Weather Index Insurance For Agriculture And Rural Areas In Lower Income Countries, American Journal of Agricultural Economics, 89(5), 1241-1247.

Capitanio F., Goodwin B.K., Enjolras G., and Adinolfi F. (2013). Risk management tools for Italian farmers: public support, problems and perspectives under CAP reform. International Agricultural Policy, n.1, 2013.

$>$ Capitanio F., Adinolfi F., Santeramo F. G. (2014): Environmental implications of crop insurance subsidies in Southern Italy, International Journal of Environmental Studies, DOI: 10.1080/00207233.2014.947737

Chatellier V. (2011) Price volatility, market regulation and risk management: challenges for the future of the CAP, International Agricultural Policy, vol. 1, pp 33-50. 
$>$ Cioffi, A., Santeramo, F. G., and Vitale, C. (2011). The price stabilization effects of the EU entry price scheme for fresh fruit and vegetables. Agricultural Economics, 42, 405-418.

$>$ Dercon, S. (2002). Income Risk, Coping Strategies, and Safety Nets. World Bank Research Observer 17(2): 141-66.

$>$ Dercon, S. (2004). Insurance against poverty. Oxford University Press 2004.

$>\quad$ Foltz, D. J. (2003). MICRO-ECONOMIC PERSPECTIVES ON TUNISIA'S AGROEXPORT STRATEGY. Food, Agriculture, and Economic Policy in the Middle East and North Africa, Volume 5, pages 209-230.

> Foltz, D. J. (2004). Credit market access and profitability in Tunisian agriculture. Agricultural Economics Vol. (30), 229-240.

$>$ Giurca, D. (2005). The adoption of the Common Agricultural Policy: Elements of pre and post accession impact. Romanian Journal of European Affairs. Vol. 5(1), 65-92.

Gurenko, E., and Mahul, O. (2004). Enabling Productive But Asset-Poor Farmers to Succeed: A Risk Financing Framework. World Bank Policy Research Working Paper 3211, February 2004.

$>$ Hsu, C., and Sandford, B. A. (2007). The Delphi Technique: Making Sense of Consensus. Practical Assessment Research \& Evaluation, 12(10).

$>\quad$ Larson D. F., Anderson J. R., and Varangis P. (2004). Policies on managing risk in agricultural markets. The World Bank Research Observer, Vol. 19(2), 199-230

$>\quad$ Lasan, N. (2012) Can Historical Institutionalism Explain the Reforms of the Common Agricultural Policy? Romanian Journal of European Affairs. Vol. 12(1), 75-85.

$>$ Lin, B. (2011). Resilience in agriculture through crop diversification: adaptive management for environmental change. BioScience, 61(3), 183-193.

> Miranda, M. J., and Gonzalez-Vega, C. (2011). Systemic risk, index insurance, and optimal management of agricultural loan portfolios in developing countries. American Journal of Agricultural Economics, 93(2), 399-406.

Mitu, N. E. (2007). Agricultural insurances in Romania: present and future aspects. MPRA working paper.

$>$ Morduch, J. (1995) Income Smoothing and Consumption Smoothing. Journal of Economic Perspectives, 9: 103-114.

$>$ NAPC (2011). The State of Food and Agriculture (Sofas). National Agricultural Policy centre (NAPC), Damascus, unpublished periodical report.

$>\quad$ Nello, S. (2002). Agriculture and EU Enlargement. Romanian Journal of European Affairs. Vol. 2(4), 5-26.

$>$ OECD (2009). Managing Risk in Agriculture: A Holistic Approach. Paris. 
$>$ Pontrandolfi, A. (2013). Risk management tools in agriculture: some reflections on the opportunities and limitations of the European commission proposal. International Agricultural Policy, n.2, 2013, 21-31.

$>$ Rollo, J. (2004). Agriculture, the structural funds and the budget after enlargement. Romanian Journal of European Affairs. Vol. 4(1), 18-28.

$>$ Sambotin, D., Alda, M., Toader, C., and lancu, T. (2013). The risk management in agriculture. Lucrări Ştiinţifice Management Agricol, 15(2), 303.

$>$ Santeramo F.G. (forthcoming 2015) On the composite indicators for food security: decisions matter! Food Reviews International. In press.

$>$ Santeramo F.G., and Cioffi A. (2012) Market crises transmission in the European vegetables sectors, PAGRI - International Agricultural Policy, Issue 2: 37-46

$>$ Santeramo F.G., Di Pasquale J., Contò F., Tudisca S., and Sgroi F. (2012) Analyzing risk management in Mediterranean Countries: The Syrian perspective. New Medit, Mediterranean Journal of Economics, Agricultural and Environment. 3: 35-40

$>$ Santeramo, F. G., Goodwin, B. K., Adinolfi, F., and Capitanio, F. (2013). Revisiting the demand for crop insurance: evidences from the Italian market. Paper presented at the 2013 AAEA Annual Meeting, August 4-6, 2013, Washington, D.C.

$>$ Spriridon, M. (2005). Rural development and agricultural policy in the context of negotiating the European Acquis. Romanian Journal of European Affairs. Vol. 5(1), 93-111.

$>$ Swinnen, J. F., and Gow, H. R. (1999). Agricultural credit problems and policies during the transition to a market economy in Central and Eastern Europe. Food Policy, 24(1), 21-47.

$>\quad$ Wattenbach, H. (2006). Farming Systems of the Syrian Arab Republic. NAPC.

$>$ World Bank (2005). Managing Agricultural Production Risk: Innovations in Developing Countries, Washington D.C.

Yazdani S. (2006), Analyzing the Impact of Structural Change in Iranian Agricultural Credit System. Agricultural Economic Review. 7: 5-14. 